Sociedades precapitalistas

ISSN: 2250-5121

publicaciones@fahce.unlp.edu.ar

Universidad Nacional de La Plata

Argentina

\title{
Entre servidumbre y trabajo asalariado: la historiografía castellana sobre las relaciones de arrendamiento en el mundo concejil bajomedieval
}

Colombo, Octavio

Entre servidumbre y trabajo asalariado: la historiografía castellana sobre las relaciones de arrendamiento en el mundo concejil bajomedieval

Sociedades precapitalistas, núm. 10,2020

Universidad Nacional de La Plata, Argentina

DOI: https://doi.org/10.24215/22505121e045

Atribución no comercial compartir igual (CC BY-NC-SA) 4.0 
Dossier: Formas de explotación del trabajo y relaciones laborales en sociedades preindustriales

\title{
Entre servidumbre y trabajo asalariado: la historiografía castellana sobre las relaciones de arrendamiento en el mundo concejil bajomedieval
}

\author{
Between serfdom and wage labor: the Castilian historiography on leasehold relations in the late medieval council \\ world
}

Octavio Colombo

DOI: https://doi.org/10.24215/22505121e045

Universidad de Buenos Aires Consejo Nacional de

Investigaciones Cientificas y Tecnológicas, Argentina

octacolombo@hotmail.com

Recepción: 10 Mayo 2019

Aprobación: 03 Septiembre 2019

Recepción: 10 Mayo 2019

Aprobación: 03 Septiembre 2019

\section{RESUMEN:}

El objetivo del presente trabajo es realizar un análisis crítico de la historiografía de las últimas décadas referida a las relaciones de arrendamiento de la tierra en los concejos castellanos de la baja Edad Media. Tales contratos vinculan a los grandes propietarios de los concejos con los campesinos de las aldeas. Se presenta en primer lugar la tesis sobre el carácter feudal de las oligarquías concejiles, del cual se derivaría el supuesto carácter servil de las formas de explotación del trabajo. Luego se presentan distintos enfoques alternativos sobre los arrendamientos, que abarcan desde su supuesto carácter de contratos libres hasta la interpretación que los asimila a relaciones asalariadas. El objetivo del análisis es mostrar que los arrendamientos son en esencia formas de movilización de la fuerza de trabajo campesina. Por lo tanto, obedecen a una racionalidad específica de control de los productores por parte de los propietarios de la tierra, cuyas modalidades concretas deben estudiarse con más profundidad.

Palabras clave: Arrendamiento, Trabajo asalariado, Castilla.

\section{Abstract:}

The objective of this paper is to carry out a critical analysis of the historiography of the last decades referring to the land lease relations in the Castilian councils of the late Middle Ages. Such contracts link the large landowners of the councils with the peasants of the villages. The thesis on the feudal character of the oligarchies is presented, from which the alleged servile character of the forms of exploitation of labor would be derived. Then, different alternative approaches to leases are exposed, ranging from their supposed character of free contracts to the interpretation that assimilates them to wage relations. The purpose of the analysis is to show that leases are essentially forms of mobilization of the peasant workforce. Therefore, they obey a specific rationality of control of producers by land owners, whose specific modalities must be studied in more depth.

KEYWORDS: Leasehold, Wage earner, Castilla.

\section{INTRODUCCIÓN}

El objetivo perseguido en este trabajo historiográfico es mostrar que la importancia y generalización de formas de explotación de la tierra a través de arrendamientos en el mundo concejil bajo medieval debe interpretarse como una forma específica de movilización de la fuerza de trabajo dependiente ${ }^{1}$. Apelamos a la idea de fuerza de trabajo dependiente o subalterna para englobar las distintas formas concretas en que la fuerza de trabajo campesina es sometida y puesta en movimiento por los propietarios de la tierra, en especial por las oligarquías urbanas bajomedievales.

La parquedad que presenta la documentación provoca que en general se acepte el predominio de los arrendamientos de diverso tipo (Bernal Estévez, 1989: 132, 213; Diago Hernando, 1993: 122; Sánchez Rubio, 1993: 255), pero no se avance en el estudio de sus características concretas. Por otro lado, como veremos, las perspectivas de interpretación adoptadas llevan a que, muchas veces, no se reconozca con claridad 
el carácter específico del vínculo. Sin embargo, la tradición historiográfica, según intentaremos demostrar en lo que sigue, presenta una gran cantidad de ideas, análisis y estudios de caso que ayudan a comprender el fenómeno del arrendamiento en el sentido indicado.

Adicionalmente, si el arrendamiento es una forma de explotación del trabajo, es también una forma de dominación del mismo, por lo que debemos destacar el aspecto contractual y a la vez coactivo del vínculo, la naturaleza económica y a la vez personal del dominio, superando la dicotomía que presenta, por un lado, "propiedad privada-relaciones contractuales-igualdad formal", y por otro, como atributos completamente distintos y hasta opuestos, "propiedad privilegiada-relaciones de dominación-coacción personal"; pero no negando uno u otro de esos términos, sino reconociendo la hibridez del fenómeno.

\section{LA TESIS FEUDAL: EL ARRENDAMIENTO COMO SERVIDUMBRE Y LOS PROPIETARIOS ABSENTISTAS}

\subsection{El arrendatario cuasi-servil}

La interpretación tal vez más extendida en la historiografía de las últimas décadas es la que postula que las relaciones de arrendamiento son formas homogéneamente feudales y serviles, lo que acompaña el supuesto carácter nobiliario de las oligarquías y su consiguiente comportamiento señorial, absentista y rentístico. Esto sería especialmente destacado en la baja Edad Media, cuando esas aristocracias concejiles han alcanzado el cenit de su acumulación territorial mediante la absorción de parcelas del campesinado pechero ${ }^{2}$. Sin embargo, los análisis encuadrados en esta perspectiva también presentan indicios que iluminan algunas especificidades que se contradicen con esta caracterización general.

Veamos algunos ejemplos. En su análisis sobre Zamora, Ladero Quesada considera que la oligarquía, propietaria de parcelas dispersas por la tierra, mantiene un patrón de residencia urbano que determina su carácter absentista y por lo tanto el predominio del sistema de arrendamientos (1991: 34). Aunque este tradicional razonamiento sea a primera vista convincente, la relación de causalidad entre sus términos es menos inmediata o necesaria de lo que parece. Ante todo, la residencia urbana no indica per se una desvinculación de la producción rural: en Ávila, por caso, el consejo no puede reunirse porque los regidores, aunque residentes urbanos, pasan sus días en la tierra ocupados en administrar sus haciendas ${ }^{3}$. La misma tarea de gestión y control suele realizarse por los representantes del propietario, amos y mayordomos omnipresentes en la documentación concejil ${ }^{4}$. El lugar de residencia no implica necesariamente absentismo, si por ello se entiende el desapego, el desinterés por o el desconocimiento de la situación de las propias tierras. Del mismo modo, como veremos en otros casos, tampoco el recurso al arrendamiento implica en sí mismo tal mentalidad antieconómica.

El análisis de Ladero parece basarse en un sistema categorial implícito en que arrendamiento, vasallaje y "servidumbre feudal" (1991: 37) se equiparan entre sí, y se contraponen al trabajo asalariado "libre" como mano de obra "ajena al sistema de relaciones sociales imperante" (1991: 98). Pero esta dicotomía se flexibiliza en el análisis concreto que hace el autor de las ordenanzas concejiles, donde se proscriben el uso y roturación de comunales y baldíos por parte de los campesinos no herederos, dado que por ello las tierras de los grandes propietarios quedaban vacías "e non les fallavan quien diese por ellas rentas" (1991: 37) . El arrendamiento aparece, por lo tanto, como una forma de explotación de la fuerza de trabajo, viable en aquellas circunstancias en que el productor carece de formas alternativas de reproducción a causa de la monopolización de los recursos sociales, lo que prácticamente equivale a la definición clásica de la relación asalariada.

Hasta cierto punto, Martínez Moro presenta un razonamiento similar al de Ladero, al afirmar el carácter señorial de la caballería villana y de la renta territorial que constituye su fuente de ingresos (1985: 242). Sin embargo, este autor presenta el interesante matiz de no hacer una distinción tajante entre las distintas 
formas que utilizan los propietarios para movilizar fuerza de trabajo. Sostiene, en cambio, que las tierras de los caballeros eran trabajadas hasta mediados del siglo XIII mayoritariamente por yugueros, una relación que "contiene elementos de aparcería", aunque el productor también recibe medios de subsistencia (1985: 241). Se trata, por lo tanto, de una forma híbrida, donde el productor aparece en parte como un rentero y en parte como un asalariado, que además en su existencia práctica "alcanza niveles personales de servidumbre" (idem). Sin embargo, esta forma sería paulatinamente desplazada en la Baja Edad Media por el arrendamiento de tierras, cambio que según el autor obedecería al incremento de la propiedad "señorial" de las oligarquías, lo que tornaría inviable la inversión necesaria para "parcelación, equipamiento y reparto" de tierras en régimen de yuguería, obligando a la oligarquía a "flexibilizar sus relaciones con la fuerza de trabajo" mediante las relaciones de arrendamiento. (1985:243-4).

Más allá de la discutible identificación de toda renta territorial como feudal o señorial, el planteo de Martínez Moro es de sumo interés en tanto presenta las modalidades de arrendamiento como formas de explotación del trabajo por parte de los propietarios, que se combinan o alternan con formas cuasiasalariadas según las cambiantes circunstancias, desplegando estrategias "flexibles" sin por ello alterar su contenido esencial. Este enfoque se ve parcialmente eclipsado, sin embargo, por la presunción de que el arrendamiento se habría impuesto dado el crecimiento de las propiedades de la oligarquía, quien sería incapaz de parcelar, repartir y equipar esas tierras incrementadas para explotarlas en régimen de yuguería. Esta hipótesis no se sostiene por varias razones, entre ellas porque desconoce el carácter disperso de las propiedades privilegiadas (lo que no haría necesario parcelarlas y repartirlas) y supone que la oligarquía no realiza también acumulaciones de dinero, animales de labor y otros medios de producción (lo que permite equiparlas). Los protocolos notariales abulenses, por ejemplo, contienen numerosas referencias a contratos de arrendamientos donde la tierra es cedida junto a bueyes, instalaciones agrarias (casas, cilleros, corrales, etc.) y una suma de dinero inicial para poner en funcionamiento la explotación ${ }^{6}$. Pero sobre todo, la hipótesis de Martínez Moro supone implícitamente (y de forma contradictoria con su propio planteo) que, en el régimen de arrendamiento, a diferencia del régimen de yuguería, el arrendatario realizaría la inversión en "equipamiento" que el propietario no estaría en condiciones de hacer, con lo que la relación se asimilaría de facto a la situación moderna del arrendatario como empresario inversor. Sin negar que esto pudiera darse en algunos casos, el rasgo mayoritario y más destacado de las formas de arrendamiento que se revela en la documentación histórica es el de una relación jerárquica de explotación del trabajo, antes que una relación igualitaria entre propietarios de tierras y propietarios de medios de producción secundarios. Esto es, de hecho, lo que da sentido a la afirmación del autor de que el cambio de yuguería a arrendamiento es una estrategia de los propietarios para "flexibilizar sus relaciones con la fuerza de trabajo", una intuición extraordinariamente acertada que implica que el arrendatario bajomedieval que reemplaza al yuguero es también, esencialmente, un proveedor de fuerza de trabajo, y no un empresario inversor.

Por su parte, Villar García también asimila las propiedades de los caballeros villanos a señoríos feudales plenos, que detentarían derechos jurisdiccionales sobre los pobladores (1986: 464, 490). Partiendo de esta definición, el autor analiza el conjunto de formas de explotación del trabajo por parte de los grandes propietarios como distintas formas que se dan en el marco de la relación servil, sea que gestionen una parcela como renteros durante todo un ciclo agrario, o sea que se contraten para la realización de una labor concreta y específica. Todas estas modalidades, del arrendatario al simple jornalero, "tenían un común denominador", a saber, su sujeción y control por parte del propietario, una dependencia que no se limita al proceso de trabajo sino que "traspasa toda la esfera vital" (1986: 506). En el mismo sentido, Barrios García plantea que las rentas que pagan los colonos por el arriendo de tierras son formas de "renta feudal [que] no pueden ser interpretadas como el simple pago por parte de los campesinos por el usufructo de la tierra del propietario", sino que dichos contratos agrarios "llevan aparejado un vínculo de dependencia personal, íntimamente ligado a la tenencia de la tierra, una relación recíproca de dominación y sometimiento" (1983: 293). 
Clemente Ramos $(1989,1990)$ comparte también la caracterización sobre el carácter señorial de los caballeros, aunque en su caso lo basa no en la posesión de derechos jurisdiccionales, sino principalmente en la propiedad de la tierra y la utilización de dependientes (1989: 69). Los caballeros, en particular, serían un grupo señorial peculiar y la relación con sus dependientes sería una forma de cuasi-servidumbre, diferenciada por el carácter contractual y temporalmente acotado del vínculo. Esta formulación expresa el carácter híbrido del vínculo a través de las "peculiaridades" que lo distinguen de la forma servil "clásica". Esto también resulta claro en el análisis de López Rodríguez, quien, a pesar de caracterizar al vínculo de arrendamiento como "señorial", sostiene que "el contrato era un medio tanto de explotar la tierra como de controlar la fuerza de trabajo" (1989: 79).

Estos análisis evidencian cómo la caracterización inmediata de toda propiedad privilegiada como señorío feudal, pese a su inexactitud, tiene el efecto positivo de permitir, por un lado, una visión unitaria de las distintas modalidades de explotación del trabajo y, por otro, de destacar el carácter a la vez económico y personal del vínculo de dependencia, diluyendo de modo más o menos implícito las dicotomías arrendatario/ asalariado, dependencia económica/dependencia personal, contrato/coacción ${ }^{7}$. Pero ello sólo se logra al costo de una abstracción homogeneizante, donde todo vínculo de clase se asimila al sometimiento feudal y donde, por lo tanto, se diluye la especificidad de la relación social. Con lo cual, en rigor, la dicotomía se anula sólo en el sentido de que uno de sus polos fagocita al otro.

\subsection{El comportamiento señorial del propietario}

Una variante más flexible de este enfoque que enfatiza el carácter feudal de la relación de arrendamiento es aquél que, sin identificar el vínculo como directamente servil, destaca sin embargo el comportamiento "señorial" o "nobiliario" del propietario, entendido como una actitud rentística, absentista, desinteresada por la gestión y el control de la producción. Por ejemplo, Sánchez Rubio afirma que la generalización de los arrendamientos debe interpretarse como la "aparición de un grupo de propietarios que abandona la tierra y obtiene a cambio de ello unas rentas" (1993: 255). También Santamaría Lancho califica a las oligarquías urbanas como rentistas (1985). Para Rucquoi, los grandes propietarios aspiran a "una vida señorial mediante la adquisición de bienes territoriales" que dan en arriendo (1997: I, 245). Martín Cea, por su lado, plantea que dar tierras en arriendo es propio del "comportamiento de los grupos privilegiados" (1996: 123), una decisión tomada en función del presunto desinterés por la gestión agraria, antes que una decisión sobre cómo explotar mejor las tierras y el trabajo ajeno. No es casual, por lo tanto, que el autor apenas mencione las formas de movilización de la mano de obra, sobre-enfatizando la autonomía productiva de la pequeña explotación, verdadero núcleo del sistema productivo, incluyendo en esa caracterización a los campesinos que deben arrendar tierras. Pero esta lectura que iguala arrendamientos con absentismo del propietario es discutible. El alejamiento del trabajo directo no implica necesariamente el alejamiento de las tareas de gestión y control del proceso de producción. Esta es una cuestión que debe tenerse presente para evitar absolutizar la autonomía de la pequeña producción, que suele darse por descontada en contextos de señorío jurisdiccional regio y fiscalidad centralizada. Cuando se afirma que el sistema jurisdiccional "no tiene apenas repercusión en los quehaceres concretos del campesino" (1996: 116), ello puede conducir a ignorar la enorme repercusión que en esos quehaceres tienen, no sólo las ordenanzas emanadas del poder jurisdiccional concejil, sino también lo que nos interesa más ahora- la enorme desigualdad en la distribución de la propiedad de la tierra. De hecho, como plantea el autor en otra ocasión, los campesinos renteros, que no disfrutan de la propiedad de la tierra sino que sólo acceden a su posesión, se encuentran en una situación que "facilita la progresiva extensión de la jurisdicción sobre la tierra a la jurisdicción sobre la persona; de ahí que muchos de ellos acaben convirtiéndose en vasallos dependientes del señor" (1983: 167). Es más, en Paredes de Nava, el Martín Cea encuentra ordenanzas en las que se establecen detalladamente las tareas que debían desarrollar los arrendatarios de 
heredades de pan llevar, y contratos de arrendamiento en los que se define "con sumo detalle las labores a realizar en los pagos de viñas" (1991: 96-7), todo lo cual indica, de modo indubitable, que el arrendamiento y la no realización del trabajo directo por parte del propietario no implica el abandono del control del proceso de producción; y que el arrendatario no es un pequeño productor autónomo, sino que está fuertemente condicionado por el concejo y por el propietario, por las ordenanzas y por el contrato, por el poder derivado del domino jurisdiccional y por el poder derivado de la propiedad de la tierra.

El estudio de Hilario Casado sobre la comarca de Burgos en la Baja Edad Media es del máximo interés en cuanto a la forma en que la idea general de una clase de propietarios "rentistas" coexiste con una enorme cantidad de análisis concretos que no se corresponden tan fácilmente con ese supuesto parasitismo. Casado señala que la formación de los grandes dominios se da principalmente a través del mecanismo económico de absorción de pequeñas parcelas de campesinos empobrecidos, que no eran expulsados de la tierra sino que seguían cultivándola a cambio de una renta (1987: 321). Este fenómeno, que se incrementa en el siglo XV, revela la "masiva penetración del capital urbano en el medio rural" (1987: 323); la propiedad de la tierra de la oligarquía se convierte entonces en "el elemento caracterizador de la comarca, siendo en algunos lugares aplastante" (1987: 480).

El autor considera, sin embargo, que la ausencia de explotación directa y la consiguiente "concepción rentística de la propiedad de la tierra" (1987: 327) impregnan a esta clase de propietarios urbanos, revelando comportamientos y actitudes señoriales contrarios al despliegue de una racionalidad económica moderna. De hecho, los contratos agrarios de arrendamiento, en especial los de más largo plazo, reflejan fielmente el contenido de las relaciones feudales tradicionales, "en las cuales los dominios útil y eminente recaen en personas o instituciones diferentes" (1987: 347). Este planteo presenta algunos tópicos que ya hemos discutido, principalmente la identificación entre arrendamiento y absentismo del rentista, como opuesto a gestión directa de la producción. Casado tiene la sensibilidad suficiente como para no identificar toda renta con renta "feudal", ni todo arrendamiento con "servidumbre", optando por una analogía más sutil, esto es, la separación del dominio útil y eminente. De este modo, abre una perspectiva para escapar a la identificación inmediata de toda relación como directa y homogéneamente "feudal", pero al mismo tiempo cancela esa posible línea de análisis al enfatizar unilateralmente el comportamiento rentístico y parasitario que sería propio de todo propietario que da en arriendo sus tierras, siendo la duración del contrato una expresión del grado de alejamiento del propietario respecto de la producción (1987: 343 ss.).

Sin embargo, como hemos mencionado, el autor presenta innumerables elementos que permiten matizar esta concepción. Puede citarse en este sentido la observación de que el empleo de mano de obra asalariada "no era rentable" para las grandes propiedades, en especial teniendo en cuenta el carácter fragmentado y disperso de las mismas, por lo que se abandona la explotación directa en beneficio del arrendamiento (1987: 342; véase también p. 503). Pero, entonces, hay que concluir que esta última opción no sería resultado de una mentalidad rentística y parasitaria, sino una opción económica perfectamente comprensible por el sistema de explotación más rentable.

Ahora bien, los arrendatarios son, al igual que los asalariados, campesinos desposeídos. Sabemos, como hemos dicho, que muchas veces los arrendatarios son los anteriores propietarios de las parcelas, que han perdido ese título por endeudamiento. Pero además, los grandes propietarios conceden "gracias" a sus arrendatarios por las rentas impagas, o les dan préstamos para comprar animales y herramientas de trabajo $(1987: 344)^{8}$. Esto indica que los propietarios o sus representantes están al tanto de la marcha del proceso productivo y de las situaciones en que es razonable cancelar una renta impaga o adelantar capital adicional. En definitiva, es probable que los propietarios practicaran distintas formas de gestión o supervisión del proceso de trabajo desarrollado por sus arrendatarios, productores desposeídos que no sólo trabajan la tierra del propietario, sino que también dependen de éste para la adquisición de instrumentos de trabajo, adelantos de dinero o moratorias de rentas atrasadas, todas formas que a su vez contribuyen a la retención y sometimiento del trabajo dependiente. En estas condiciones no parece haber una diferencia cualitativa, 
en cuanto al dominio del propietario sobre el productor y la relativa falta de autonomía de éste, entre el arrendatario y el asalariado (sea éste yuguero o trabaje por un contrato de servicio). Antes bien, parecen dos métodos distintos de remuneración y control de la fuerza de trabajo agraria, que no reflejan mentalidades ni estrategias radicalmente diferenciadas, sino decisiones concretas entre formas de explotación alternativas pero fuertemente emparentadas.

Esta hipótesis se corresponde con el análisis que hace Casado sobre los contratos de arrendamiento, señalando que en los de largo plazo la renta es más elevada que en los de corto plazo, lo que indica que el largo plazo de los contratos no es indicio del comportamiento rentístico y absentista del propietario sino la opción más rentable para él (1987: 353). Del mismo modo, la renta en especie, en un contexto inflacionario como el de la baja Edad Media, beneficia al propietario, resguardándolo frente a la desvalorización de la moneda y permitiéndole sacar ventaja de la venta especulativa del producto (1987: 352, 505). El autor también señala que con la recuperación económica de fines del siglo $\mathrm{XV}$, se tienden a estancar la proporción de contratos de largo plazo, que ya no serían atractivos, en beneficio de los de corto y mediano plazo, lo que también muestra que la duración de los contratos es sensible a la coyuntura económica y no una mera función invariable de la actitud absentista de los propietarios $(1987: 354)^{9}$. En definitiva, invertir en tierras y darlas en arriendo "era un negocio no sólo seguro sino también beneficioso" (1987: 505), afirmación que torna innecesario apelar a una supuesta mentalidad señorial anti-económica para explicar la proliferación de esa forma de explotación.

En definitiva, Casado expresa el punto más alto de la tesis del arrendamiento "feudal”, limitando la analogía a la distinción entre dominio útil y eminente, y enfatizando en cambio el ideal nobiliario del comportamiento de la oligarquía. Su análisis concreto, sin embargo, ilustra la naturaleza de los arrendamientos como forma de control y explotación del trabajo campesino dependiente por parte de los grandes propietarios. El autor percibe los intereses económicos que están detrás de las decisiones de la oligarquía, pero intenta restarles importancia por su incompatibilidad con el imaginario “señorial”. Sin embargo, es posible eludir esa dicotomía y postular que la adopción de formas más efectivas de control y dominación del trabajo tienen un objetivo económico indubitable, sin por ello suponer la vigencia trans-histórica de las características propias del empresario capitalista moderno.

\section{EXPLICACIONES ALTERNATIVAS: CONTRATO LIBRE, TRABAJO FORZADO, TRABAJO} ASALARIADO

Los aportes historiográficos que acabamos de reseñar dan cuenta del enfoque esencial de la renovación de la disciplina a partir de la década de 1980. Como es sabido, esa perspectiva se construyó en gran medida en oposición a los planteos de la escuela institucionalista, que enfatizaba la peculiaridad del caso español, a partir de la supuesta ausencia de feudalismo y del predominio de "hombres libres" en las estructuras concejiles de la meseta central. Debe señalarse, sin embrago, que la negación institucionalista del feudalismo castellano no impedía reconocer la existencia de vínculos de dependencia social y económica, incluso personal, entre los pobladores. Era perfectamente posible compatibilizar la ausencia de instituciones formales feudo-vasalláticas, con la existencia tanto del régimen señorial (especialmente al norte del Duero) como, en general, de relaciones de dependencia entre propietarios y campesinos pobres (en la Extremadura). De este modo, paradójicamente, como puede verse en las investigaciones de Guglielmi (1967), se daba cuenta del carácter social y económico específico del vínculo laboral, lo que constituía un gran aporte, aunque sólo para contrastarlo con la situación feudal del resto de Europa, dado que en Castilla esa dependencia no ponía en cuestión el carácter formalmente libre del sujeto dependiente. 


\subsection{El arrendamiento como contrato económico}

Una parte de la historiografía renovadora posfranquista rescató el aspecto esencial y positivo de esta diferenciación, no ya para negar el sistema feudal como tal, pero sí para evitar que el reconocimiento de su existencia se convirtiera en una caracterización apriorística de todo vínculo jerárquico como servil. Monsalvo Antón, por ejemplo, parte de la distinción entre renta señorial y renta "de la heredad" o económica, correspondiendo esta última al rendimiento de la tierra (1988: 99). Esto sin duda tiene utilidad para evitar la homogeneizante caracterización de "feudal" para toda extracción, pero a la vez introduce una dicotomía demasiado excluyente entre formas de dominación social y formas de arrendamiento económico contractual. El mismo autor reconoce, por ejemplo, que "los contratos de servicios" no excluyen relaciones de dependencia o subordinación personal, teniendo en cuenta que se trata de "contratos" pero, aclara, en un contexto "feudal" (1988: 106). Esta correcta observación, sin embargo, es igualmente aplicable a los contratos de arrendamiento que involucran a campesinos pobres, que también se dan en un contexto feudal, y cuya distinción con los contratos de servicios es, como venimos argumentando, más formal que sustantiva. Monsalvo, sin embargo, se esfuerza por distinguir radicalmente las relaciones de arrendamiento, en las que "sin mediar vínculo personal alguno" se crearía una relación entre personas no sólo "libres sino también situadas en un plano de equidad jurídica", lo que daría como resultado un contrato de "estricto significado económico" (1988: 107). Pero el mismo autor señala más adelante que los herederos empobrecidos que "agora se avían tornado renteros" caían "bajo diversas formas en niveles de dependencia económica y pauperización real" (1988: 118); ese empobrecimiento, por lo tanto, aparece como causa de la conversión de los campesinos en renteros, pero también en jornaleros u otras modalidades de trabajo ("contratos de servicio”, a los que el autor sí reconoce un contenido de dependencia personal), lo que indica que todas esas formas comparten un elemento jerárquico común, y que son en definitiva distintas modalidades de movilización de fuerza de trabajo. Es arbitrario, por tanto, atribuir a algunas de esas formas (los contratos de servicio) elementos de dependencia personal y sumisión, y a otras (los contratos de arrendamiento) la supuesta ausencia de esos elementos. Esta dicotomía se explica menos por la evidencia histórica que por la tendencia a generalizar la diferencia que existe en la sociedad moderna entre relación asalariada y arrendamiento capitalista de la tierra. Por lo tanto, se puede considerar que existen otros elementos además del "rendimiento económico" que intervienen en la determinación de la renta de un arrendamiento contractual; en especial, los elementos que hacen al carácter jerárquico de la relación y a la capacidad de dominio del propietario sobre el productor, que no es un dato accesorio o un abuso particular, sino un atributo estructural de los arrendamientos contractuales pero aun así "feudales". El carácter económico y contractual de la relación no implica la ausencia de formas de dominio y coacción personal sobre el productor, como bien habían señalado los exponentes de la escuela institucionalista.

El propio Monsalvo aporta numerosos elementos para pensar la situación de otro modo, por ejemplo cuando observa que los propietarios tenían dificultades para conseguir mano de obra "no sólo de jornaleros, sino de criados y renteros" (1988: 434), lo que da cuenta mucho mejor del aspecto esencial que comparten esas diversas modalidades de movilización y uso de la mano de obra. Esta perspectiva, contraria a la distinción tajante entre asalariados, contratos de servicio y arrendamiento, se aplica mejor, por ejemplo, al acertado análisis que hace el autor del interés de la oligarquía en acaparar pastos como forma de competencia por la fuerza de trabajo rural, dado que el propietario podría ofrecerlos para el ganado de labor de sus renteros o asalariados (1988: 435). En casos como éste, la distinción entre renteros y asalariados se vincula más con la forma de remuneración de la mano de obra que con diferencias cualitativas en la relación social o en la condición del productor, diluyendo la dicotomía entre renta económica como relación contractual igualitaria e impersonal versus dependencia social y personal del productor empobrecido frente al propietario.

Aunque, como vimos antes, la identificación que realiza la "tesis feudal" del arrendamiento con la "servidumbre feudal" carezca de fundamento, tal perspectiva tiene el paradójico efecto positivo de presentar 
esa relación inmediatamente como una forma de explotación del trabajo y, por tanto, a la renta como un mecanismo de apropiación del excedente. Por contraste, Monsalvo capta el aspecto económico y contractual del arrendamiento, al diferenciar la renta "de la heredad" de la renta "feudal", pero lleva la disección demasiado lejos y ubica a la primera como un pago vinculado al rendimiento productivo (como en el caso de la renta diferencial capitalista), expresión de una relación impersonal y formalmente igualitaria, en lugar de verla como una forma de control y explotación del trabajo ajeno. En nuestra opinión, es necesaria una revisión conceptual y empírica que permita disolver estas dicotomías, destacando el contenido de las diversas formas de arrendamiento como relaciones donde el fundamento en la propiedad de la tierra, y el carácter económico y contractual del vínculo, están en función de la movilización y explotación de una fuerza de trabajo semiproletarizada y del establecimiento de relaciones de dominación duraderas y de carácter personal sobre los productores. No estamos ante una servidumbre feudal, pero tampoco ante relaciones de arrendamiento en el sentido moderno de formas de alquiler y uso de la tierra, sino ante formas de dependencia donde los propietarios intentan encuadrar una fuerza de trabajo tendencialmente "libre" (en el sentido de parcial o totalmente desposeída).

\subsection{El arrendamiento y el control del trabajo}

En este sentido, el análisis de Asenjo González sobre el concejo de Segovia muestra con especial claridad tanto el carácter generalizado de los arrendamientos como su significado esencial en tanto forma de subordinación del trabajo. La autora afirma que la gran mayoría de los campesinos, aunque pudieran ser propietarios de pequeñas parcelas, "trabajan en tierras arrendadas" (1986: 162), y que el arrendamiento "era el sistema de explotación agraria más extendido" (1986: 340). Pero además, los renteros estaban sometidos "a una velada dependencia que disminuiría notablemente su capacidad de acción” (idem). Claramente, la situación no se asemeja a un contrato libre e impersonal entre iguales.

En este plano, las ordenanzas de Segovia mencionan los "pegujales", un fenómeno presente en las ordenanzas abulenses y de por sí interesante en cuanto a las cuestiones conexas que revela ${ }^{10}$. Los pegujales son pequeñas porciones de tierra que el dueño de una propiedad cede al rentero o aparcero para que las cultive por su cuenta y en su beneficio, como parte de su remuneración (1986: 149). Este caso puede interpretarse como un indicio de la yuxtaposición entre la figura del rentero o aparcero y la del asalariado: al conceder una pequeña parcela para labrar por su cuenta y para su propia subsistencia, el arrendatario se revela como un desposeído que recibe un salario en forma de tenencia.

Por lo tanto, al igual que en el caso de los pastos privados analizado por Monsalvo, aquí también los pegujales operan como forma de atraer y fijar mano de obra rural. Esto es lo que se desprende de la disposición, presente en distintas ordenanzas, según la cual los pecheros no debían efectuar trabajos ni acudir a labrar con sus animales para cualquier heredero sino a cambio de un pago en dinero ("salvo por sus dineros"; Asenjo, 1986:163). Como señala la autora, esta norma intenta evitar que el dominio sobre las tierras que detentan los grandes propietarios se transforme en un "dominio sobre los hombres que las ocupaban y las trabajaban” (1986: 163), obligando a estos renteros a trabajar sin salario en las tierras directamente explotadas por los propietarios. Este revelador análisis permite explicitar algunos supuestos de la situación, que clarifican su naturaleza. Es claro, ante todo, que el dominio de la tierra tiende a transformarse en un dominio sobre los productores, que se materializa concretamente en la forma de servicios en trabajo exigidos a los renteros. Aunque la naturaleza del vínculo sea contractual y económica, y no haya elemento jurisdiccional, feudal o señorial alguno, la propiedad de la tierra habilita una forma de servidumbre económica contractual, que es menos excéntrica de lo que un habitual esquematismo dicotómico haría creer. Que las ordenanzas concejiles intenten bloquear políticamente la extensión de esta relación de explotación es sintomático en cuanto a que las condiciones económicas y las tendencias de desarrollo espontáneas de la propiedad territorial tienden 
a reproducirlo y extenderlo. Se comprueba entonces que la relación de arrendamiento es una forma de acceder a mano de obra, fijándola en tierras propias, una forma que encuentran los grandes propietarios de internalizar la oferta de trabajo y de cancelar la inestabilidad del mercado laboral. Este intento de controlar y regularizar el flujo de trabajo dependiente en función de las necesidades de la gran propiedad territorial dispersa, entonces, debe también leerse sobre el telón de fondo de la resistencia campesina a someterse a la explotación, la tendencia a sustraerse de la relación laboral dependiente o al menos a aprovechar el carácter discontinuo y escaso de la oferta de trabajo para beneficiarse en la negociación mercantil puntual, aquella en la que se intercambian servicios laborales concretos "por dineros" (como dice la ordenanza) ${ }^{11}$. Los propietarios, en cambio, prefieren cancelar este mercado 'instantáneo' en beneficio del establecimiento de relaciones duraderas de sumisión, instalando a los trabajadores como renteros para garantizar la previsibilidad del suministro de mano de obra ${ }^{12}$. Aunque podría razonablemente especularse sobre si esta estabilización tenía también alguna ventaja para el productor, lo cierto es que los propietarios apelan a todos los medios a su alcance para imponerla, lo que genera la impresión de que los eventuales beneficios para ambas partes, de existir realmente, estaban distribuidos de un modo muy desigual ${ }^{13}$.

Adicionalmente, el caso de los pegujales analizado por Asenjo muestra que no hay una elección excluyente entre explotación directa o indirecta de la tierra, entre gestionar inmediatamente la producción o desentenderse de ella dando la tierra en arriendo, con la consiguiente suposición de que una u otra de estas alternativas revelaría actitudes de clase contrapuestas. Por el contrario, lo que podemos ver aquí es una estrategia económica y productiva unitaria, donde las distintas formas de gestión de la tierra se complementan en función de una racionalidad que contempla, simultáneamente, tanto la explotación de la tierra como las condiciones específicas de dominación de la fuerza de trabajo. En definitiva, la diferencia entre el rentero y el asalariado "por dinero" podría ser, simplemente, que el primero es una forma más eficiente, por ser más estable y duradera, de someter al trabajo, al menos en las condiciones de un mercado de trabajo irregular e imperfecto, donde la relación asalariada no resulta un mecanismo adecuado para el sometimiento social global de la clase de los productores.

Esto no sólo es válido para el caso de grandes propiedades constituidas por parcelas dispersas, donde el costo del control cotidiano de un incipiente proletariado agrario aun no disciplinado podría ser altísimo y tornar más rentable la opción de instalar colonos sometidos al pago de rentas fijas en grano (como es el caso mayoritario en los protocolos notariales abulenses citados), sobre quienes es suficiente un control más laxo y periódico. También en el caso de propiedades concentradas, la internalización de la oferta de mano de obra puede tener enormes ventajas para el propietario, al desentenderlo de la necesidad de acudir a un mercado frágil y discontinuo, asegurándose un suministro constante de trabajo y producto por parte de los campesinos instalados en sus tierras. Esto explica la formación de términos redondos en los que el objetivo no es despoblar la tierra para su usufructo ganadero, sino la creación de verdaderas aldeas privadas, núcleos de población sometidos de conjunto al poder del propietario que están documentados en diversos casos. Las ordenanzas abulenses, por ejemplo, mencionan "las aldeas e lugares que son de algunos omes, que son apartados sobre sý” ${ }^{\prime 4}$. De este modo, el propietario, al recurrir al mercado de tierras como sustituto del mercado de trabajo, dando en arriendo tierras a cambio de la permanencia y continuidad de la fuerza de trabajo, logra satisfacer su necesidad de mano de obra a pesar de la falta de disciplinamiento mercantil del productor, pero en ausencia de poderes feudales de mando asociados a la propiedad territorial. Esta doble carencia resume, en cierto sentido, las condiciones de hibridez de esta forma de explotación de trabajo, que combina elementos de la disciplina del mercado y del dominio sobre la persona, justamente porque no se basa plenamente ni en aquélla ni en ésta forma de control social. 


\subsection{Arrendamientos y trabajo asalariado}

A partir de estas consideraciones, podemos valorar el análisis realizado por Oliva Herrer (2002) para Tierra de Campos, tal vez el autor que de modo más directo y frontal plantea el predominio absoluto del trabajo asalariado en el campo bajo medieval. La formulación de Oliva puede verse como la contracara de la tesis feudal analizada más arriba: lo que en esta última se presenta como servidumbre, Oliva lo presenta como trabajo asalariado.

Esta manera de plantear el problema contiene elementos de indudable interés. Ante todo, parte de reconocer la desigualdad en la distribución de la tierra como el factor primordial en la comprensión de la estructura social y de la relaciones de producción. Oliva destaca que al menos dos terceras partes de los vecinos carecen de medios autónomos de subsistencia (2002: 163). Por lo tanto, deberían recurrir al trabajo asalariado. Este modo de explotación se correspondería con "el predominio casi absoluto de la explotación directa" como modo de gestión de la propiedad (2002: 194); el uso de trabajo asalariado en las explotaciones de mayores dimensiones como sistema habitual y no sólo de modo estacional; y la consiguiente proletarización de una amplia capa del campesinado, concepción que el autor contrapone a aquellas que restringen este concepto a la sociedad capitalista moderna (2002: 202-3).

Esta audaz formulación adolece, sin embargo, de una ambigüedad que debilita la fuerza de sus conclusiones: nos referimos a la falta de clarificación en torno al concepto de trabajo asalariado. Oliva parece operar implícitamente con dos acepciones distintas. Por un lado, parece considerar que el trabajo asalariado es la consecuencia inmediata y directa de la desposesión total o parcial de un sector significativo del campesinado; comprobada ésta, se sigue aquél. Aquí trabajo asalariado es sinónimo en general de trabajo "libre" en el sentido marxiano de trabajo desposeído. Por otro lado, sin embargo, el autor parece operar con una definición mucho más restrictiva, que iguala trabajo asalariado al obrero que trabaja por un jornal, incluso "siendo habitual su remuneración en metálico" (2002: 206), y lo contrapone a otras figuras laborales como el rentero, el yuguero, el criado, etc. A diferencia de la anterior, esta es una definición mucho más restrictiva, que alude a una forma específica en la que puede ser puesta en movimiento la fuerza de trabajo desposeída de medios de producción, en beneficio de los propietarios de la tierra. Oliva ha querido mostrar la extensión de la relación asalariada más allá de la sociedad moderna, lo que es muy acertado, pero ha asumido la forma asalariada moderna como la única propiamente tal.

Por contraste con esta definición restrictiva, sin embargo, en diversas oportunidades la acepción amplia del término parece más acorde con la evidencia histórica presentada por el autor. Es el caso de la ordenanza que manda que "qualquier vezino o morador en esta dicha villa que tomare arar o cavar viñas o tierras" deba trabajar la tierra "como lo han de fazer los que arriendan de cofradias viñas", una disposición que el autor cita de forma privilegiada como demostración del predominio del trabajo asalariado (2002: 194, 204), "del que en principio sólo parecen estar exentas las cofradías del lugar" (2002: 194). Parece excesivamente forzado, sin embargo, interpretar que la referencia a los vecinos que "tomaren" tierras para labrar se esté contraponiendo a los que las “arriendan” de las cofradías. Más bien parece que la ordenanza iguala ambas situaciones, mandando que quien arriende tierras de otro vecino (las "tomare") lo haga con las mismas obligaciones que los que las arriendan de las cofradías. Esto sin duda puede tomarse como expresión del predominio del trabajo asalariado, pero solo si aceptamos que en estas condiciones el arriendo es una forma de trabajo asalariado, donde la parcela constituye el salario del productor.

Del mismo modo, Oliva toma como expresión indubitable del predominio de la explotación directa asociada al trabajo asalariado, una referencia a que los regidores no podrán venir a reunirse al regimiento en momentos álgidos del calendario agrario (2002: 195); una mención de contenido idéntico a la que, como ya hemos dicho, se encuentra en la documentación abulense ${ }^{15}$. Destacando correctamente esta imbricación de los propietarios en el proceso de producción, el autor da por descontado que esta gestión directa demuestra el predominio del trabajo asalariado en su forma moderna, cuando en realidad puede postularse sin dificultad 
que esas prácticas de gestión y control de la fuerza de trabajo se ejercen sobre una diversidad de formas de trabajo dependiente, sean jornaleros ocasionales, trabajadores contratados para tareas específicas, renteros u otro tipo de dependientes. Por último, puede así también entenderse con más claridad la figura del pego, oficial concejil garante del cumplimiento de los contratos, cuya existencia demostraría según Oliva "la función primordial que el trabajo asalariado desempeña" (2002: 204), dado que interviene en la ejecución de todo lo vinculado a "todo trabajo o todo alquiler e trabajo de cuerpo o manos e de bestias e qualquier manera de alquiler", lo que sin duda avala la centralidad del control y disciplinamiento de la relación laboral como función central de dicho oficial, pero da cuenta a la vez de la amplitud de las formas concretas que el sometimiento del trabajo ajeno puede adoptar, más allá de la forma asalariada en sentido restringido del pago en metálico por el uso de la fuerza de trabajo del productor en un lapso de tiempo determinado.

En definitiva, el análisis de Oliva Herrer resulta de enorme utilidad no bien se reconoce que el trabajo asalariado en sentido abstracto o general está compuesto por una multiplicidad de formas de explotación y control del trabajador dependiente, parcial o totalmente desposeído (Banaji, 1997). Oliva ha cuestionado acertadamente la identificación inmediata entre capitalismo y trabajo asalariado, pero ha aceptado implícitamente la forma capitalista (moderna) del trabajo asalariado. Esto no sólo lleva a forzar la evidencia en pos de una interpretación unívoca de la forma asalariada, sino también a minimizar los elementos de dependencia personal que caracterizan a estos vínculos laborales. Si el análisis del autor conserva un aire de excentricidad modernista, creemos, es solo por la falta de una presentación reflexiva y razonada de este problema; hecho esto, su análisis se torna mucho más sólido y convincente.

La tesis del trabajo asalariado también ha sido desarrollada, con un alcance más condicionado, por Astarita (1994). En rigor, el objetivo central de este autor era determinar la condición de clase de los caballeros villanos de la Extremadura histórica, y no el régimen laboral agrario de los concejos como tal. Sin embargo, al caracterizar a ese estamento como un sector superior del campesinado, basado en formas de propiedad alodiales o independientes sobre la tierra, desarrolla el argumento según el cual esas propiedades de mediana extensión se explotan mediante trabajo asalariado. Este aspecto de su planteo resulta de relevancia para lo que aquí estamos discutiendo. Por contraste con las tesis feudales y absentistas, Astarita destaca correctamente que la figura del mayordomo revela el involucramiento del propietario en el proceso de producción, a través de la organización, gestión y control del mismo por parte de su representante. Este sistema de "explotación económica directa de los caballeros" (1994:38) se efectiviza a partir de la explotación de un segmento social de campesinos miserables que "en términos globales se comprende como asalariado" (1994:34). Esta perspectiva es de suma importancia, tanto porque conecta el fenómeno asalariado con la existencia de un estrato social total o parcialmente desposeído, como porque enfatiza el carácter global o general de una caracterización que admite distintas formas particularizadas. En este aspecto el análisis de Astarita permitiría resolver la ambigüedad que habíamos encontrado en el estudio de Oliva Herrer, al presentar la forma moderna como forma hegemónica del asalariado. Astarita plantea, en cambio, que la relación asalariada puede plasmarse en distintas figuras, como es el caso del yuguero o el apaniaguado, y que incluso admite distintas modalidades de remuneración, "mediante pago de salarios o bien participando de parte de los frutos de la producción" (1994: 39), lo que supone que no sólo los yugueros, sino en general las distintas formas de aparcería, deberían ser consideradas modalidades diferentes de remuneración de la fuerza de trabajo. El autor considera incluso que esta variabilidad en la modalidad de remuneración es uno de los rasgos que determina el carácter premoderno del vínculo laboral, lo que no anula su contenido económico y contractual. En el mismo sentido, la existencia de "cláusulas constrictivas" y normas coactivas que rodean a esta forma asalariada corresponden a las "condiciones generales preburguesas" (1994: 47) del contexto histórico.

Este análisis, congruente con la perspectiva que venimos desarrollando en este trabajo, es sin embargo parcialmente contradictorio con el argumento que despliega Astarita cuando trata específicamente de las relaciones de arrendamiento. Estas no son mencionadas, significativamente, en el apartado sobre relaciones laborales, sino en otro titulado "Régimen jurisdiccional y beneficios complementarios". Allí, el autor 
reconoce que "los miembros de la aristocracia local combinan formas de heredades bajo explotación directa a cargo de mayordomos o caseros, junto con otras arrendadas por renteros", pero en la medida en que los caballeros tenían vedado el desarrollo de poderes jurisdiccionales privados de tipo señorial, "esta relación individual de rentas no tenía posibilidades efectivas de desarrollarse plenamente” (1994: 59). En este punto, el razonamiento del autor parece estar inducido por el marco polémico en que se inscribe, esto es, la tendencia historiográfica dominante que considera que toda relación de arrendamiento es en esencia una forma de servidumbre feudal. De hecho, Astarita acepta que el arrendamiento "se presenta como un reflejo de las relaciones feudales implementadas por los señores" (1994: 60), pero tiende a minimizar su importancia y a negar su capacidad de "desarrollarse plenamente" como forma feudal. Este modo de enfrentar la tesis feudal asume, al igual que esta última, que el arrendamiento es -o está en vías de ser- una relación puramente "feudal", no económica-contractual sino basada en condiciones extra-económicas.

En definitiva, el arrendamiento tendría un contenido histórico y social opuesto al del trabajo asalariado. Sin embrago, el propio argumento de Astarita, al analizar la relación asalariada, permite un enfoque distinto de la cuestión. Allí, como hemos visto, el autor afirmaba que era también un asalariado el productor desposeído remunerado con una parte de la cosecha. Pero la aparcería es, en definitiva, una forma de arrendamiento, que no puede considerarse radicalmente distinta a las formas con renta fija, que de hecho son muy habituales ${ }^{16}$. También en este último caso encontramos productores desposeídos que toman a renta tierras, instalaciones, animales de labor e incluso a veces una suma de dinero inicial, como ya hemos mencionado que se puede ver en diversos documentos. Aquí el arrendatario solo aporta su fuerza de trabajo y la de su familia (un elemento no menor en las ventajas que reporta para el propietario), mientras que el remanente de la producción luego de pagar la renta debe considerarse como su salario. En la medida en que las fluctuaciones de la producción impactan de lleno en la subsistencia del productor, la renta fija opera en estos casos como un sustituto del control laboral, antes que como un estímulo a la inversión (como ocurre en la empresa capitalista). La renta fija podría ser, por lo tanto, una forma contractual especialmente apta cuando el incremento de la propiedad territorial de la aristocracia concejil se realiza a través de la acumulación de parcelas dispersas, evitando el incremento excesivo de los costos de vigilancia del conjunto de las explotaciones.

En estos casos, por lo tanto, la renta no es "inherente a la posesión campesina de la tierra" (Astarita, 1994: 45) como es el caso de la renta feudal, sino que, a la inversa, se deriva de la desposesión del productor y constituye una forma trasmutada de la relación asalariada. Este planteo, que Astarita admite explícitamente en el caso de la renta a partes, es igualmente aplicable a otros tipos de arreglo contractual en el mismo contexto histórico y social: si la renta a partes efectivamente corresponde a un asalariado que es remunerado "participando de parte de los frutos de la producción" (1994: 39), en casos similares la renta fija corresponde a un asalariado que es remunerado con el remanente de la producción. La existencia de relaciones asalariadas y de relaciones de arrendamiento no constituye un juego de suma cero, como expresiones de relaciones productivas antagónicas, sino que se complementan en el marco de una racionalidad coherente de explotación de los sectores pobres de la comunidad por parte de los propietarios acomodados. Esta perspectiva permite dar cuenta de un complejo sistema de relaciones productivas, cuyas formas específicas deben investigarse con más detalle.

\section{A MODO DE CONCLUSIÓN}

Más allá del contexto polémico en que se desarrolló, la interpretación de las relaciones de arrendamiento como formas serviles, que realizó buena parte de la historiografía castellana a partir del último cuarto del siglo XX, daba cuenta del contenido de esas relaciones como formas de explotación del trabajo. Sin embargo, su especificidad quedaba diluida en una abstracta mención al poder jurisdiccional y la "coacción extraeconómica" ejercida por el propietario. Otras elaboraciones, como hemos visto, brindaron elementos alternativos muy valiosos para avanzar en el estudio de la especificidad del fenómeno, pero no llegaron 
a conformar una visión alternativa coherente, aunque revalorizaron el aspecto contractual y económico del fenómeno, abriendo las puertas a la comprensión de la pluralidad de relaciones sociales que pueden desarrollarse en un contexto que no por ello deja de ser indiscutiblemente feudal. Más allá de las fortalezas y debilidades de cada enfoque particular, que ya hemos resaltado, existen entonces sólidos fundamentos para encarar el estudio histórico de las formas económicas premodernas de explotación del trabajo dependiente (de las cuales los arrendamientos estudiados serían una modalidad específica), como momento histórico en el largo y sinuoso proceso de formación de una fuerza de trabajo sometida y disciplinada por el mecanismo salarial moderno a los propietarios de los medios de producción. La estructura feudal concejil, con su pasado de sociedad de frontera y la consiguiente ausencia de señoríos territoriales significativos, bien puede ser un espacio privilegiado para el estudio de esas formas híbridas de dominación del trabajo.

\section{REFERENCIAS}

Asenjo González, M. (1986). Segovia. La Ciudady su Tierra a fines del Medievo. Segovia: Excma. Diputación Provincial.

Astarita, C. (1994). Caracterización económica de los caballeros villanos de la Extremadura castellano leonesa (siglos XII-XV). Anales de Historia Antigua y Medieval, 27, 11-83.

Banaji, J. (1997). Modernizing the Historiography of Rural Labour: An Unwritten Agenda. En Bentley, M. (ed.). Companion to Historiography. Londres-Nueva York: Routledge, 83-96.

Barrios García, Á. (1983-1984). Estructuras agrarias y de poder en Castilla: el ejemplo de Ávila (1085-1320). 2 vols. Salamanca: Universidad de Salamanca.

Bernal Estévez, Á. (1989). El concejo de Ciudad Rodrigo y su Tierra durante el siglo XV. Salamanca: Diputación de Salamanca.

Carrasco Tezanos, A. (2004). Propiedad campesina y medianos propietarios en la Castilla central entre los siglos XV y XVI. Studia Historica. Hist. medieval, 22, 109-149.

Casado Alonso, H. (1987). Señores, mercaderes y campesinos. La comarca de Burgos a fines de la Edad Media. Valladolid: Junta de Castilla y León.

Clemente Ramos, J. (1989). Estructuras señoriales castellano-leonesas. El realengo (siglos XI-XIII). Salamanca: Universidad de Extremadura.

Clemente Ramos, J. (1990). La sociedad en el fuero de Cáceres (siglo XIII). Cáceres: Instituto cultural "El Brocense".

Diago Hernando, M. (1993). Soria en la Baja Edad Media. Espacio rural y economía agraria. Madrid: Editorial Complutense.

Fox, H. (1995). Servants, Cottagers and Tied Cottages during the Later Middle Ages: Towards a Regional Dimension. Rural History, 6, 125-154.

García de Cortázar, J. A. (1988). La sociedad rural en la España medieval. Madrid: Siglo XXI.

García Oliva, M. D. (1990). Organización económica y social del concejo de Cáceres y su Tierra en la Baja Edad Media. Cáceres: Institución Cultural "El Brocense".

Guglielmi, N. (1967). La dependencia del campesino no propietario (León y Castilla - Francia. Siglos XI-XIII). Anales de Historia Antigua y Medieval, 13, 95-187.

Jones, P. J. (1968). From Manor to Mezzadria: a Tuscan Case-Study in the Medieval Origins of Modern Agrarian Society. En Rubinstein, N. (ed.). Florentine Studies. Politics and Society in Renaissance Florence. Londres: Faber and Faber, 193-241.

Ladero Quesada, M. F. (1991). La ciudad de Zamora en la época de los Reyes Católicos. Economía y gobierno. Zamora: Instituto de Estudios Zamoranos "Florián de Ocampo".

López Rodríguez, C (1989). La organización del espacio rural en los fueros de la Extremadura castellana. En la España medieval, 12, 63-94. 
Luis López, C. (1987). La Comunidad de Villa y Tierra de Piedrabita en el tránsito de la edad Media a la Moderna. Ávila: Institución Gran Duque de Alba.

Martín Cea, J. C. (1983). El campesinado castellano de la cuenca del Duero. Aproximación a su estudio durante los siglos $X I I I$ al $X V$. Valladolid: Consejo General de Castilla y León, Servicio de Publicaciones.

Martín Cea, J. C. (1991). El mundo rural castellano a fines de la Edad Media. El ejemplo de Paredes de Nava en el siglo $X V$. Valladolid: Junta de Castilla y León.

Martín Cea. J. C. (1996). El trabajo en el mundo rural bajomedieval castellano. En AA. VV., El trabajo en la Historia. Salamanca: Ediciones Universidad de Salamanca.

Martínez Alier, J. (1974). Peasants and Labourers in Southern Spain, Cuba and Highland Peru. Journal of Peasant Studies, 1 (2), 133-163.

Martínez Alier, J. (1978). Renda de la terra, explotació i excedent. Estudis d'historia agraria, 1, 38-63.

Martínez Moro, J. (1985). La Tierra en la comunidad de Segovia. Un proyecto señorial urbano (1088-1500). Valladolid: Secretariado de Publicaciones de la Universidad de Valladolid.

Monsalvo Antón, J. M. (1988). El sistema político concejil. El ejemplo del señorío medieval de Alba de Tormes y su concejo de Villa y Tierra. Salamanca: Ediciones Universidad de Salamanca.

Oliva Herrer, H. R. (2002). La Tierra de Campos a fines de la Edad Media. Economía, sociedad y acción politica campesina. Valladolid: Universidad de Valladolid.

Olmos Herguedas, E. (1998). La Comunidad de Villay Tierra de Cuéllar a fines de la Edad Media. Poder político concejil, ordenanzas municipales y regulación de la actividad económica. Valladolid: Universidad de Valladolid.

Razi, Z. (1981). Family, Land and the Village Community in Later Medieval England. Past \& Present, 93 (1), 3-36.

Rucquoi, A. (1997). Valladolid en la Edad Media, dos tomos, Valladolid: Junta de Castilla y León.

Sánchez Rubio, M. (1993). El concejo de Trujillo y su alfoz en el tránsito de la Edad Media a la Edad Moderna. Badajoz: Universidad de Extremadura.

Santamaría Lancho, M. (1995). Del concejo y su término a la comunidad de Ciudad y Tierra: surgimiento y transformación del señorío urbano de Segovia (siglos XIII-XVI). Studia Historica. Hist. medieval, 3, 83-116.

Villar García, L. M. (1986). La Extremadura castellano-leonesa. Guerreros, clérigos y campesinos (711-1252). Valladolid: Junta de Castilla y León.

Yun Casalilla, B. (1987). Sobre la transición al capitalismo en Castilla. Economía y sociedad en Tierra de Campos (1500-1850). Valladolid: Junta de Castilla y León.

\section{DOCUMENTOS CITADOS}

AA. VV. (1988-1999). Documentación del Archivo Municipal de Avila. 6 volúmenes. Ávila: Institución Gran Duque de Alba.

AA. VV. (1995-2010). Documentación medieval abulense en el Registro General del Sello. 22 volúmenes. Ávila: Institución Gran Duque de Alba.

Del Ser Quijano, G. (1998). Documentación medieval en Archivos Municipales Abulenses. Ávila: Institución Gran Duque de Alba.

Jiménez Hernández, S., y Redondo Pérez, A. (1992). Catálogo de Protocolos Notariales del Archivo Histórico Provincial de Ávila (Siglo XV). 2 tomos. Ávila: Institución Gran Duque de Alba.

Monsalvo Antón, J. M. (1990). Ordenanzas medievales de Ávila y su Tierra. Ávila: Institución Gran Duque de Alba.

\section{Notas}

1 Como perspectiva general, véanse los siguientes estudios: Jones, 1968; Banaji, 1997; Martínez Alier, 1974, 1978; Fox, 1995; Razi, 1981. 
2 García de Cortázar (1988: 204); menciones particulares en Barrios García (1984: 147, 176); Luis López (1987: 378-81); García Oliva (1990: 88 ss.), entre otros. Un ejemplo documental de absorción de numerosas heredades por un propietario poderoso: del Ser Quijano (1998), Archivo de Burgohondo, docs. 10 a 22, septiembre de 1469.

3 AA. VV. (1995-2010), vol. II, doc. 4, 21-9-1479: los regidores "tienen sus heredamientos en las aldeas e lugares de la tierra... e muchas vezes en la dicha \#ibdad non ay regidores que se junten a entender e proveher en las cosas de la dicha \#ibdad", p. 21.

4 Por ejemplo, Monsalvo (1990), doc. 21, 21-5-1346, p. 22; doc. 3, 1346-1384, p. 30, entre otros.

5 El reparto de tierras comunes para labranza es una práctica habitual, véase otro caso en AA. VV. (1995-2010), vol. IV, doc. 63, 11-4-1487.

6 Jiménez Hernández y Redondo Pérez (1992), docs. 1644, 1771, 1848, 1878, 1879, 1881, 1895, 1931, 1935, 1944, 1945, 1987, 2004, 2025, 2039, 2040, 2077, entre otros.

7 Según Villar García, por ejemplo, "los yugueros eran, ante todo, siervos de su señor, traspasando su dependencia a la simple relación económica" (1986: 503), una expresión algo imprecisa pero que apunta en el sentido indicado.

8 Menciona también condonación de rentas atrasadas Martín Cea (1983: 131). En Valladolid, Rucquoi (1997: II, 222), a pesar de inclinarse por la tesis del comportamiento rentista del patriciado, presenta el caso de un gran propietario que concede préstamos a sus arrendatarios "con vistas a mejorar el rendimiento agrario".

9 Carrasco Tezanos (2004: 142, 145) registra también la preferencia de las oligarquías locales por los arrendamientos de corto y mediano plazo desde las últimas décadas del siglo XV.

10 Monsalvo (1990), doc. 1, 21-5-1346.

11 Como señala Olmos Herguedas para el caso de Cuellar, el concejo realiza una "injerencia directa y decisiva" en las relaciones de producción, con un marcado "sesgo clasista" a favor de los propietarios, restringiendo la movilidad de trabajo, prohibiendo dedicarse a otras tareas en momentos críticos del calendario agrario y regulando los salarios para evitar que suban a causa de la debilidad de la oferta (1998: 273-5).

12 Para el período moderno, el análisis de Yun Casalilla plantea elementos similares en cuanto al lugar de la pequeña explotación, no como un sector autosuficiente, sino como un mecanismo útil para la fijación "de los efectivos demográficos y a la reproducción de la fuerza de trabajo campesina... contribuyendo a abaratar los costos laborales, externalizando de las grandes propiedades los costos de reproducción de la fuerza de trabajo" (1987: 132).

13 Este escueto comentario no tiene la intención de dar por cerrado el tema (cuya explicitación aprovechamos para agradecer a un evaluador anónimo de este trabajo), en especial porque no se limita a mera cuestión de los beneficios materiales inmediatos para una y otra parte (acceso regular a la mano de obra versus acceso a una tenencia y/o a un ingreso modesto pero regular durante el año), sino al problema más amplio y espinoso del disciplinamiento de la fuerza de trabajo, es decir, al aspecto cualitativo del sometimiento del productor y no sólo al aspecto cuantitativo del reparto del producto. Esperamos en el futuro poder desarrollar este punto del modo en que lo amerita.

14 Monsalvo (1990), doc. 3, 1346-1384, p. 29. También doc. 18, febrero-marzo de 1487, Ley 21, sobre términos redondos, donde se menciona la existencia de habitantes en los mismos (p. 88). AA. VV. (1995-2010), vol. IX, doc. 87, 17-4-1494, se menciona otro término redondo poblado. Véase también Diago (1993: 113, 124).

15 AA. VV. (1995-2010), vol. II, doc. 4, 21-9-1479.

16 Monsalvo (1990: 83), doc. 18, febrero-marzo de 1487, Ley 14: "qualesquier yugueros o renteros o medieros, que tovieren a renta o yuguería o medierýa qualesquier herdad".

\section{BY-NC-SA}

